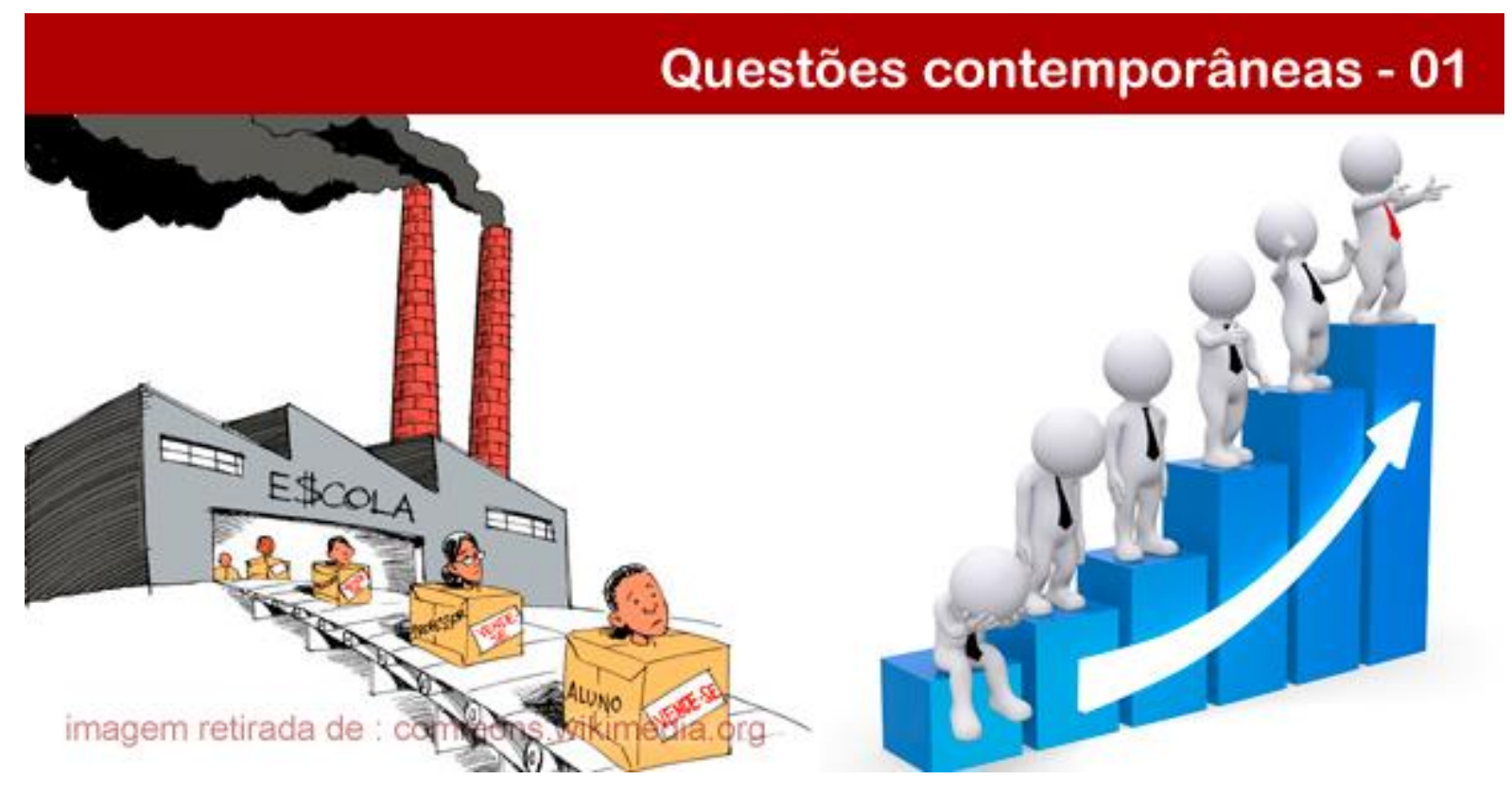

\title{
A HIPERFORMATIVIDADE E SUAS DISPERSÕES: RACIONALIDADES FORMATIVAS PARA ALÉM DA ESCOLARIZAÇÃO
}

\begin{abstract}
André Bocchetti
Doutor em Educação pela Universidade de São Paulo (USP). Professor Adjunto da Faculdade de Educação da Universidade Federal do Rio de Janeiro (UFRJ) e Professor colaborador do Programa de Pós-Graduação Profissional em Gestão e Avaliação da Educação Pública da Universidade Federal de Juiz de Fora (UFJF). Email: andreb.ufrj@gmail.com.
\end{abstract}

Resumo: O estudo analisa, partindo sobretudo de algumas reflexões realizadas por Michel Foucault, aquilo que denomina hiperformatividade: a maneira pela qual os discursos da formação, compreendida como ato de interferência educativa nos modos de existir, tem se difundido para bem além dos espaços formais de escolarização. Para isso, delineia diferentes modos de dispersão dos enunciados que formam o dispositivo formativo na atualidade. Partindo-se da análise de documentos legais e de reportagens veiculadas pela revista Veja, foram mapeados movimentos de espalhamento que parecem estar na base de certa cultura hiperformativa na contemporaneidade: dispersões pela complexidade, que ampliam o espectro de saberes fundamentais à formação; pela (auto)qualificação do ato formativo, que funcionam pela qualificação e mensurabilidade da própria ação de formação; pela liquidez das aquisições formativas, que tornam efêmeras as conquistas de formação, fazendo do preparo um movimento de sucessivos reinícios; e pelo engajamento individual, que constroem um senso de responsabilidade diante do mundo e da coletividade, estabelecendo as aquisições formativas necessárias a sua consecução. Tais dispersões constroem formas de integração entre formatividade, laboralidade e modos de existir, dando à noção de formação um sentido de preparo bem atento aos ideais mercadológicos dos discursos de matriz neoliberal, que precisa ser foco de estudos que se debrucem sobre a formatividade contemporânea.

Palavras-chave: Políticas educacionais. Dispositivo formativo. Dispersões formativas. Hiperformatividade.

\section{HIPERFORMATIVINESS AND ITS DISPERSIONS: FORMATIVES RACIONALITIES BEYOND THE SCHOOLING}

Abstract: The study analyzes, based on Michel Foucault's studies, what it could be called "hiperformativiness": the way formation discourses, understood as acts of educational interference in modes of existence, it has spread beyond the formal schooling spaces. In this way, the article draws different means of dispersion of the statements that shape the formation device today. Starting from the analysis of legal documents and articles published by

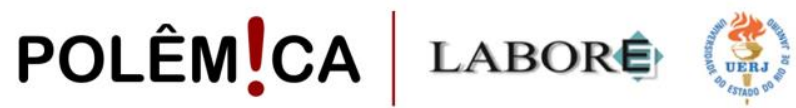

Polêmica - Revista Eletrônica da Uerj - Rua São Francisco Xavier, 524, $1^{\circ}$ andar bloco D, sl.1001 • Tels.: +55 21 2334-4088/4087 • http://www.e-publicacoes.uerj.br/index.php/polemica/index http://www.labore.uerj.br • laboreuerj@yahoo.com.br 
Veja magazine, spreading movements were mapped. They seem to be at the heart of certain hiperformative culture in contemporary society. There are dispersions by complexity, which expand the spectrum of basic knowledge about formation; dispersions by the formative (self)qualification, which work by the maximization and measurability of the formation act; dispersions by the liquidity of formative acquisitions that make ephemeral formation achievements, turning the preparation process on a movement of successive restarts; and dispersions by the individual engagement that build a sense of responsibility before the world and the community, establishing the formation acquisitions necessary to achieve them. Such dispersions build forms of integration between formativeness, labor activities and ways to exist, giving the notion of formation a sense of careful preparation to Market ideals, common in the discourse of neoliberal matrix, which must be the focus of studies to look into the contemporary formativeness.

Keywords: Educational policies. Formation device. Formative dispersions. Hiperformativiness.

\section{Introdução}

Nas últimas duas décadas as discussões pautadas na ideia de formatividade, sobretudo a partir da figura docente, tem se avultado no país. O tema vem sendo alvo de abordagens que incluem debates acerca do financiamento, modelos e tecnologias envolvidas nas dinâmicas de formação dos professores; reflexões que passam pela avaliação de propostas, validação de currículos e implementação de políticas; análises de ferramentas, processos e subjetividades em formação. A “gestão da identidade dos professores”, de que fala Lawn (2001), passa por toda essa produtividade.

Mas a questão formativa, sempre premente nas agendas e nas propostas que se avultam por todo o território nacional e além dele, em muito ultrapassa os espaços de formação voltados à docência ou a própria sala de aula. $\mathrm{O}$ dispositivo formativo - esse “mingau que mistura o visível e o enunciável" (DELEUZE, 2005, p. 47) acerca da formatividade -, de amplo alcance, parece se viabilizar por uma série de movimentos de espalhamento que levam consigo, para bem além dos espaços escolares, racionalidades fundamentais à produção de modos de existir bastante característicos da contemporaneidade. É a partir deles que se delineia esta análise: um estudo que, partindo dos indícios de certos regimes discursivos presentes em documentos legais e oficiais de origem educacional, e dos enunciados de uma importante revista não especializada brasileira ${ }^{1}$, procura investigar alguns

\footnotetext{
${ }^{1}$ Trata-se da Revista Veja, escolhida em virtude de sua abrangência: uma reportagem veiculada pela Associação Nacional de Editores de Revista, em 2009, menciona a Veja como a terceira maior revista de informação do mundo, apontando estudos que projetam seu número total de leitores em cerca de 8 milhões (ANER, 2009). Para esta pesquisa, foram consideradas edições completas da publicação, analisadas em suas diversas sessões e publicadas entre os anos de 1990 e 2015, que culminaram em noventa e duas reportagens de maior relevância, aproximadas neste trabalho dos demais documentos legais e oficiais aqui citados; as análises de tais arquivos foram norteadas por construções e reelaborações sucessivas de categorias analíticas que apontaram para a formação de regimes distintos de dispersão dos saberes formativos, que organizam as sessões deste artigo.
}

\section{POLÊM!CA $\mid$ LABORË}

Polêmica - Revista Eletrônica da Uerj - Rua São Francisco Xavier, 524, $1^{\circ}$ andar

bloco D, sl.1001 • Tels.: +55 21 2334-4088/4087 • http://www.e-publicacoes.uerj.br/index.php/polemica/index http://www.labore.uerj.br • laboreuerj@yahoo.com.br 
dos modos de dispersão das racionalidades formativas ${ }^{2}$. Tal empreitada nasce do anseio em apreender o modo como, atualmente, as práticas de formatividade se difundem em espaços e relações cada vez mais cotidianas, incidindo de forma microscópica na existência diária do ser humano comum, e assim constituindo uma hiperformatividade que não cessa de colocar o sujeito em um estado de constante preparação de si diante da realidade.

Observar as formas de dispersão das racionalidades no interior de um dispositivo significa, de certa forma, seguir as linhas a partir das quais as relações microfísicas do poder compreendido enquanto "ação sobre ações", em termos foucaultianos (FOUCAULT, 1995, p. 243) - se materializam em determinada época, na forma de enunciados de verdade. Tais materializações, embora comumente desprovidas de um estrategista que as constitua em sua emergência, não deixam de ser tomadas por práticas que visam a governar os sujeitos entendendo-se que o sentido da ideia de "governo", na ótica foucaultiana de análise, não se limita à institucionalização da ação sobre os outros, mas ao modo como tal ação se dá em diferentes espaços sociais. A "arte de governar os homens" nasce, por sinal, muito cedo na história ocidental: Foucault (2007) a localizaria como uma questão fundamental já nos séculos XV e XVI, traduzindo-a, em seus estudos, a partir da noção de "governamentalidade", esse esforço de condução (proveniente de diversos espaços sociais) associado a um conjunto de mentalidades, interessado em “criar sujeitos governáveis através de várias técnicas desenvolvidas de controle, normalização e moldagem das condutas das pessoas" (FIMYAR, 2009, p. 38).

As análises foucaultianas localizam, dentre os diversos efeitos dos regimes de governamentalidade que surgem no século XV, uma figura particularmente cara à lógica de funcionamento das técnicas de governar na contemporaneidade: o Estado - que, ao invés de ser tomado como o lugar do nascimento das racionalidades que irão de alguma forma coibir ações no interior da sociedade, é observado como mais um dos efeitos das práticas de governamento, ao mesmo tempo em que materializa mais um elemento social que, como

\footnotetext{
${ }^{2}$ Em seus estudos sobre o funcionamento microfísico das relações de poder, Michel Foucault (1995) contrapõe o exercício analítico das "racionalidades específicas" (p. 233) que compõem um dispositivo ao anseio, tido por ele como "estéril", em "julgar a razão" (p. 233), como se fosse possível contrapô-la a uma não-razão. É com base, portanto, em tal noção de racionalidade, que a define como elemento contingente às produções de saberes de uma época e aos campos de lutas nas quais estão elas implicadas que se utiliza, nessa pesquisa, o termo "racionalidade formativa" e suas derivações.
}

\section{POLÊM!CA $\mid$ LABORE}


tantos outros, se institucionaliza pelo uso de agenciamento de saberes possíveis em uma época.

Dois modos de operação das racionalidades estatais, explanados nos estudos de Foucault, talvez sejam especialmente valiosos ao funcionamento de um dispositivo que encontra nos anseios de formatividade e em sua cada vez mais evidente dispersividade suas possibilidades de constituição. Um deles está pautado em certo sentido geral da razão de Estado que, ao menos desde o século XVIII, se viu associada a um desejo de "não governar demais" (FOUCAULT, 2008, p. 18), à busca de critérios de economicidade a partir dos quais fosse possível, com o mínimo de esforços, controlar as formas de subjetividade de súditos ou cidadãos. Outro está atrelado às estratégias que colocam a questão da vida e de sua gestão como base de tais formas de se governar. Foucault (1988) chama de "biopolítica" a esse tipo de ação que encontra nas populações e nas operações específicas em torno da sexualidade, também desde o século XVIII, seu maior foco. Tomando como base o dispositivo da sexualidade e suas formas de operação - ora focadas no estudo das taxas de fecundidade, natalidade e morte, ora construídas sobre as individualidades e seus comportamentos sexuais -, o autor posiciona os mecanismos biopolíticos, pautados nas regulações populacionais, ao lado daqueles de natureza anatomopolítica, focados na disciplina corporal. O jogo entre ambos, no interior daquilo que Foucault chama "biopoder", engloba a miríade de operações que colocam o "fazer viver" como base das políticas pautadas no governo de todos e de cada um.

É, portanto, no contexto de uma analítica que une desejos de economicidade e anseios pela gestão da vida que as análises de diversos dispositivos, na contemporaneidade, parecem fazer sentido. Isso inclui os diferentes caminhos de dispersão das racionalidades formativas aqui observados, a partir dos quais a questão da formação parece alcançar formas bem peculiares e cotidianas de organização dos modos de existir na contemporaneidade.

\section{Dispersões pela complexidade}

Alguns dos movimentos dispersivos em torno das racionalidades formativas estão pautados na ampliação do espectro quantitativo de saberes fundamentais a serem buscados por processos formativos diversos. A constituição do dispositivo formativo, no âmbito das instituições educacionais, parece incluir a composição de uma série de enunciados

\section{POLÊM!CA $\mid$ LABORE}


socialmente legitimados que apontam para a necessidade de aquisição de um conjunto cada vez maior de saberes, sempre reposicionados e reelaborados por guias e experts.

Veja-se, por um lado, o caso do professor, talvez o grande indivíduo a ser formado em nosso tempo. A cada movimento legal que se debruça sobre a questão dos saberes docentes, novos objetos surgem, constituindo um quadro complexo na formação de um profissional sempre plural e atento àquilo que a cientificidade didática é capaz de lhe apresentar. Algumas nuanças de tal "mapa de conhecimentos" estão abaixo evidenciadas:

Quadro - 1: Algumas exigências legais para a formação docente.

\begin{tabular}{|c|c|}
\hline Documento Legal & Elementos temáticos da formação docente \\
\hline $\begin{array}{l}\text { Resolução } \quad \text { CEB/CNE } \\
\text { 02/1999 (BRASIL, 1999a) }\end{array}$ & $\begin{array}{l}\text { Conhecimentos da "filosofia, sociologia, história e psicologia } \\
\text { educacional, da antropologia, da comunicação, da } \\
\text { informática, das artes, da cultura e da linguística, entre } \\
\text { outros" (art. 3, inc. III). }\end{array}$ \\
\hline $\begin{array}{l}\text { Lei 9795/1999 (BRASIL, } \\
\text { 1999b) }\end{array}$ & "dimensão ambiental" (art. 8 inc. I). \\
\hline $\begin{array}{l}\text { Resolução CEB/CNE 02/2001 } \\
\text { (BRASIL, 2001) }\end{array}$ & $\begin{array}{l}\text { Conhecimentos relativos à educação especial, } \\
\text { "constituição de redes de apoio" (art. 8 inc. VI), } \\
\text { "temporalidade flexível do ano letivo" (inc. VII) "atividades } \\
\text { que favoreçam, ao aluno que apresente r altas } \\
\text { habilidades/superdotação, o aprofundamento } \\
\text { enriquecimento de aspectos curriculares" (inc. IX). }\end{array}$ \\
\hline $\begin{array}{l}\text { Decreto 5626/2005 (BRASIL, } \\
\text { 2005) }\end{array}$ & Libras \\
\hline $\begin{array}{l}\text { Resolução CP/CNE }{ }^{4} \text { 01/2006 } \\
\text { (BRASIL, 2006a) }\end{array}$ & $\begin{array}{l}\text { "(...) aplicação, em práticas educativas, de conhecimentos de } \\
\text { processos de desenvolvimento de crianças, adolescentes, } \\
\text { jovens e adultos, nas dimensões física, cognitiva, afetiva, } \\
\text { estética, cultural, lúdica, artística, ética e biossocial". }\end{array}$ \\
\hline $\begin{array}{l}\text { Resolução FNDE }{ }^{5} \text { 20/2006 } \\
\text { (BRASIL, 2006b) }\end{array}$ & $\begin{array}{l}\text { "(...) ações de Inovações Educacionais, Aceleração da } \\
\text { Aprendizagem, Educação para o Trânsito, Educação Fiscal e } \\
\text { Saúde”. }\end{array}$ \\
\hline $\begin{array}{l}\text { Portaria INEP }{ }^{6} 128 / 2008 \\
\text { (BRASIL, 2008) }\end{array}$ & (...) "ecologia", "globalização", "redes sociais", "terrorismo". \\
\hline
\end{tabular}

Fonte: Elaboração própria.

Mas a complexidade presente nos discursos da formação docente escapa aos espaços escolares. Nas relações familiares, por exemplo, a multiplicação das necessidades formativas pode alcançar outras formas, ainda mais longevas, de funcionamento. De bases conceituais

\footnotetext{
${ }^{3}$ Câmara de Educação Básica do Conselho Nacional de Educação.

${ }^{4}$ Conselho Pleno do Conselho Nacional de Educação.

${ }^{5}$ Fundo Nacional de Desenvolvimento da Educação.

${ }^{6}$ Instituto Nacional de Estudos e Pesquisas Educacionais Anísio Teixeira.
}

\section{POLÊM!CA LABORË}


diferenciadas - ora dispostas a partir de uma moralidade de ordem filosófica, ora apresentadas por meio de uma normatização de parâmetros também científicos -, as orientações dadas às famílias, no que tange a seu modo de ação como lugar de formação, são múltiplas. À determinada reportagem (A CONSTRUÇÃO, 1996, p. 84) se torna possível, então, construir elementos normativos explícitos quanto ao preparo das crianças: "os pais que desejam que seus filhos aprendam uma segunda língua devem começar o ensino antes dos 10 anos", apontam suas análises, com base em achados de natureza neurofisiológica; ao que, por sinal, se evidencia o novo nicho mercadológico: "Não é a toa que o ensino de inglês para bebês de 1 ano tornou-se relativamente comum entre famílias abastadas" (p. 84).

Ao se multiplicarem, os saberes-objetos de formação se aglutinam em uma lógica de complexificação que se avulta no interior do dispositivo formativo. Se "a vida profissional resume-se atualmente a um aprendizado constante" (O QUE ESTÁ, 1993, p. 88), é porque sobre ela - e, da mesma forma, sobre o modo de agir com os filhos, na escola, junto aos colegas, em um evento festivo - pode-se constituir não só um repertório inesgotável de saberes mas, com ele, uma natureza formativa necessariamente complexa, que obriga a um debruçar constante sobre a questão da formação, seja por parte dos especialistas, da sociedade em geral ou do próprio formando.

A construção atual da complexidade formativa traz consigo algumas características. Em primeiro lugar, legitima um movimento sobre si mesmo que sempre aponta para um grande exercício de transformação. É em seu nome que a revista alerta a todos os empregados que será necessária, de alguma forma, a realização de "uma gigantesca reengenharia individual" para poder atentar ao momento de intensas transformações nas empresas (A REVOLUÇÃO, 1994, p. 89). Tais reconstruções de si são, nesse caso, voltadas à escolarização formal mais elementar, associadas a lugares de nobreza e valoração de postos de emprego: "sem o $1^{\circ}$ grau completo está difícil arrumar emprego até na construção civil. Para funções de comando, só se qualifica quem tem formação universitária” (p. 91).

A complexidade formativa torna inaceitável tudo o que não possui um dinamismo efervescente. Aquilo que não é continuado se torna, por si mesmo, insuficiente e, por vezes, impróprio. A experimentação estanque não pode ser admitida, pois faz com que a formação enquanto produto não se mantenha em longo prazo. Entre o demasiadamente longo reservado apenas para os processos associados à educação básica e à formação em nível

\section{POLÊM!CA $\mid$ LABORE}


superior - e o breve, há um tempo a ser valorizado pelas estratégias formativas, suficientemente amplo para garantir a sensação de formação, e suficientemente reduzido para evitar a sensação de completude; um tempo específico das aquisições formativas, consonante ao sentimento moderno de que "tudo pode ser feito, mas nada pode ser feito de uma vez por todas" (BAUMAN, 1998, p. 37).

\section{Dispersões pela (auto)qualificação do ato formativo}

Alguns dos movimentos fundamentais à constituição dos saberes legitimados pelo discurso formativo funcionam pela qualificação da própria ação formativa, em um jogo que procura, ainda que em um contexto de intensa profusão, definir seus limites e tornar cada vez mais mensuráveis seus domínios e estratégias necessárias. Mais uma vez, as intervenções realizadas no interior dos discursos associados à aquisição dos saberes docentes parecem especialmente profícuas nesse sentido, motivando institucionalizações, programas, estratégias e novos corpos de conhecimento, constituídos a partir de delineamentos oficiais diversos. Tome-se, como um dos muitos exemplos possíveis, a elaboração da Política Nacional de Formação de Profissionais do Magistério da Educação Básica (BRASIL, 2009a), que inclui, já em seu dispositivo original, a constituição dos Fóruns Estaduais Permanentes de Apoio à Formação Docente, constituídos, entre outras responsabilidades, para "coordenar a elaboração e aprovar as prioridades e metas dos programas de formação inicial e continuada para profissionais do magistério, e demais questões pertinentes ao bom funcionamento dos programas" (BRASIL, 2009b).

A qualificação dos saberes de formação se dá em grande parte pela construção de discursos que permitam circunscrever o máximo de conhecimentos possíveis no amplo domínio das aquisições formativas - dos quais os recalcitrantes esforços para a constituição de Bases Curriculares Nacionais são apenas um exemplo no universo da escolarização. Se no caso das políticas públicas de formação docente essa operação parece estar pautada, sobretudo, na institucionalização de órgãos e instrumentos qualificadores, nas ações cotidianas que ultrapassam os espaços formalmente voltados à educação parece haver mecanismos ainda mais microscópicos de tangibilização desses saberes. A cada ação realizada, importa garantir-lhe um caráter específico de formação, presente, por exemplo, na

\section{POLÊM!CA $\mid$ LABORE}


reportagem (A BRINCADEIRA, 1992) que, discutindo o valor dos jogos eletrônicos na infância, argumenta sobre sua importância:

(...) a criança aprende a lidar com várias alternativas e passa a ser capaz de fazer análises múltiplas, em vez da simples análise sequencial. Ela tem que pensar no seu próximo passo enquanto envia o comando para o sistema motor, ao mesmo tempo em que faz uma correção e reorienta uma jogada mal planejada (p. 91).

A operação que valora o ato formativo e legitima sua multiplicação funciona a partir de dois elementos discursivos peculiares. Transforma, em primeiro lugar, a realidade formativa do sujeito em um elemento qualificador per si: o fato de "estar em formação" já imprime certa valoração positiva às narrativas que sobre ele se estabelecem. Tudo pode, então, ser analisado a partir daquilo que provoca no indivíduo em termos de preparo, fazendo da formação uma taboa de medida da existência. Além disso, reiterados enunciados procuram qualificar a formatividade sobretudo a partir de critérios de demarcação científica. Veja-se, mais uma vez, a questão do uso dos games, na qual a ação da expertise focada em conhecimentos de natureza neurocientífica assume um papel preponderante na definição dos benefícios associados a tais brinquedos eletrônicos:

(...) os videogames estimulam o hemisfério esquerdo do cérebro, o lado que comanda a expressão da linguagem, o raciocínio matemático, a lógica, a rapidez de pensamento, a estratégia e o raciocínio tecnológico. Os neurônios do outro hemisfério cerebral comandam aspectos intuitivos, éticos, artísticos ou filosóficos (A BRINCADEIRA, 1992, p. 91).

O que esse tipo de relação sempre formativa com a realidade instaura é uma necessidade de contribuição, em termos de preparação do indivíduo, que passa a funcionar como elemento chancelador de atitudes vindas de todos os lugares sociais. A família é, sem dúvida, um desses espaços por excelência, que termina por se constituir em objeto de formação, ao qual se colocará a serviço uma nova profusão de saberes, evidente, por exemplo, nos variados enunciados que clamam pela ação dos pais na formação de seus filhos e de si mesmos, que terminam por produzir um certo acartilhamento da formatividade necessária aos leitores da publicação:

Quadro - 2: Acartilhamento da formação familiar.

\begin{tabular}{|c|l|}
\hline A cartilha... & Seus enunciados \\
\hline ...que ensina a ser pai & Telefone para casa; $(. .$.$) Dê autoridade à empregada para vetar a$ \\
(PAIS, 1997, p. 88). & bagunça; $(. .$.$) Só dê presente de natal; (...) Crie rotina; (...) Não$ \\
\hline
\end{tabular}

\section{POLÊM!CA $\mid$ LABORE}

Polêmica - Revista Eletrônica da Uerj - Rua São Francisco Xavier, 524, $1^{\circ}$ andar

bloco D, sl.1001 • Tels.: +55 21 2334-4088/4087 • http://www.e-publicacoes.uerj.br/index.php/polemica/index http://www.labore.uerj.br • laboreuerj@yahoo.com.br 


\begin{tabular}{|c|c|}
\hline & leve trabalho para casa. \\
\hline 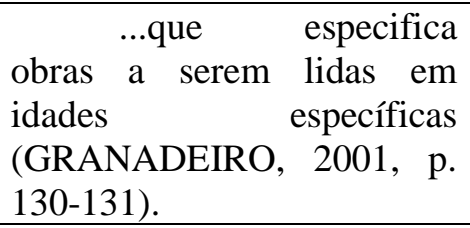 & $\begin{array}{l}\text { Até } 3 \text { anos: Bambi, Ursinho Puff, Dumbo, Cachinhos de ouro; } 3 \\
\text { e } 4 \text { anos: João e Maria, Branca de Neve e os sete anões, Os três } \\
\text { porquinhos, Chapeuzinho vermelho. }\end{array}$ \\
\hline $\begin{array}{l}\text {...que ensina } \text { a } \\
\text { reconhecer os filhos que } \\
\text { usam drogas (NA } \\
\text { CARTEIRA, 1991, p. 47). }\end{array}$ & $\begin{array}{l}\text { Eles se afastam dos antigos amigos; (...) criam novos vínculos; } \\
\text { (...) vivem em "falta ou excesso de dinheiro"; (...) têm notas } \\
\text { baixas; (...) evidenciam repentinas mudanças de rotina; (...) } \\
\text { vivem em um contexto de falta de diálogo. }\end{array}$ \\
\hline $\begin{array}{l}\text {...que ensina o adulto } \\
\text { a estar preparado para } \\
\text { permanecer no emprego } \\
(\text { NETO, 1996, p. 119). }\end{array}$ & $\begin{array}{l}\text { (...) faça tudo o que estiver ao seu alcance para viajar e, } \\
\text { principalmente, estudar fora (...) leia jornais. Informações gerais } \\
\text { são muito valorizadas hoje (...) a curiosidade a respeito de outros } \\
\text { departamentos de sua empresa é essencial (...) se é a empresa } \\
\text { que está defasada, é bom procurar emprego logo numa mais } \\
\text { moderna. (...) Cuide da aparência pessoal. (...) É preciso ter } \\
\text { ambição. }\end{array}$ \\
\hline $\begin{array}{l}\text {...que ensina a } \\
\text { preparar os filhos para o } \\
\text { mercado de trabalho (NETO, } \\
\text { 1996, p. 121). }\end{array}$ & $\begin{array}{l}\text { O profissional criativo é o mais procurado. Por isso, aulas de } \\
\text { canto, de teatro ou de filosofia não devem ser consideradas } \\
\text { supérfluas pelos pais. (...) Inibição é um fator que atrapalha a } \\
\text { vida das pessoas no trabalho. Há algumas maneiras de corrigir } \\
\text { esse problema nas crianças. (...) Aguçar a curiosidade nas } \\
\text { crianças também é importante (...). }\end{array}$ \\
\hline $\begin{array}{l}\text {...que ensina a avaliar } \\
\text { a melhor escola para o filho } \\
\text { (ANTUNES, 2006, p. 124- } \\
\text { 125). }\end{array}$ & $\begin{array}{l}\text { É fundamental que a escola enfatize a leitura e recomende ao } \\
\text { menos um livro não didático por mês. (...) que prepare a criança } \\
\text { para ter uma vida globalizada. (...) (o pai deve) saber a } \\
\text { quantidade diária de tarefa de casa. (...) informar-se sobre a } \\
\text { média da escola no ENEM (...). }\end{array}$ \\
\hline $\begin{array}{l}\text {...que ensina a lidar } \\
\text { com os filhos, } \\
\text { cotidianamente (SOUZA; } \\
\text { VIEIRA, 2008, p. 58). }\end{array}$ & $\begin{array}{l}\text { Demonstre orgulho pelas conquistas de seus filhos. Elogie a } \\
\text { criança. Dê atenção à criança e esteja sempre presente. Ajude } \\
\text { seu filho a atingir objetivos. Não projete suas expectativas nos } \\
\text { filhos. Encoraje seu filho a ser sociável e a se posicionar. } \\
\text { Valorize a imaginação da criança. Recompense seus filhos. } \\
\text { Incentive a amizade entre os irmãos. Nunca use de sarcasmo } \\
\text { com as crianças. }\end{array}$ \\
\hline
\end{tabular}

Fonte: Elaboração própria.

Ao homem a formar, o dispositivo formativo reservou ainda uma extensa série de elementos discursivos que o tornam apto a um exercício cotidiano de mensuração. Ser capaz de calcular(se), contar(se), ajuizar(se). Sua existência, então, se torna um exercício constante de escolhas entre aquisições formativas - sendo a seletividade desse homo eligens uma de suas maiores angústias (BAUMAN, 2001), em um tempo no qual até frente às regras sociais será "preciso saber escolher as que funcionam" (SOUZA; VIEIRA, 2008, p. 54). Para tais seleções, será sempre fundamental, acima de tudo, que a mensurabilidade alcance as inúmeras possibilidades formativas com as quais se depara. A formatividade está, portanto, calcada na

\section{POLÊM!CA $\mid$ LABORE}


produção efetiva de saberes sobre saberes que, dando forma a programas, currículos e matrizes educativas, ensinam ao sujeito em formação que ser de algum modo mensurável deve ser a prerrogativa maior de qualquer possibilidade de aquisição formativa que dele se aproximar. Um caso bastante elucidativo é apresentado por um documento da UNESCO (2009) que constitui bases curriculares para programas de desenvolvimento das competências necessárias aos professores no que concerne ao uso das Tecnologias da Informação e Comunicação (TIC). Tal texto articula padrões de competência a partir de seis componentes: "Política e Visão", "Currículo e Avaliação", "Pedagogia", "TIC", "Organização e Administração" e "Desenvolvimento Profissional do Docente" (p. 7). Cada componente é, por sua vez, correlacionado com a natureza de cada um dos programas propostos: "Alfabetização em Tecnologia" (p. 9-11), "Aprofundamento do Conhecimento" (p. 12-14) e "Criação de Conhecimento" (p. 15-17). Desses cruzamentos, são geradas matrizes a partir das quais as competências são propostas. No programa de Alfabetização em Tecnologia, no âmbito das TIC, por exemplo, são apresentadas onze competências, como "usar uma ferramenta de busca para fazer uma pesquisa booleana por palavra-chave" (p. 9) ou "localizar os pacotes de programas educacionais mais adequados e os recursos da Web e avaliá-los em relação à sua precisão e alinhamento com os padrões curriculares, e ajustá-los às necessidades de alunos específicos" (p. 10). Para cada competência, são apresentados exemplos de métodos a partir dos quais os formadores desses professores devem atuar, visando sua aquisição. São, no total, sessenta e duas competências.

Por meio de movimentos de mensurabilidade, se produz uma formatividade vasta, que multiplica ainda mais as aquisições formativas, levando o indivíduo a uma exigência cotidiana sobre si mesmo, que envolve cálculos e análises de possibilidades donde derivam suas escolhas de formação. E mais do que isso: a produção de tais necessidades instaura novos domínios de saberes a adquirir, aos quais um frutífero mercado de formação pode, continuamente, se dedicar.

\section{Dispersões pela liquidez das aquisições}

Se, por um lado, há movimentos dispersivos que não cessam de multiplicar as aquisições formativas, há por outro aqueles que funcionam por torná-las sempre efêmeras, fazendo do preparo individual um movimento de sucessivos reinícios, pautados, sobretudo, na

\section{POLÊM!CA $\mid$ LABORE}


insegurança inerente ao movimento de manter-se em formação. Instalam-se, constantemente, no consumismo formativo, elementos que funcionam como obstáculos que incitam à continuidade, transformando a existência em um agregado de desafios a enfrentar. Os atuais enunciados formativos constituem aprioristicamente no sujeito uma relação consigo e com o mundo, que o coloca em situação de desvantagem, a partir da qual sempre se poderá lutar pelo alcance de uma situação mais favorável, que, no entanto, se estabelece, imediatamente, como nova insuficiência a vencer. O caminho para a existência segura é um voo em queda livre que jamais atinge o solo.

A operação fundamental, na construção da insegurança pessoal, é a desqualificação do preparo do indivíduo diante da realidade global. Se há sempre que se falar em novas necessidades do mundo contemporâneo, é porque a partir delas se pode afirmar, por exemplo, que as tais exigências globais "estão cristalizadas no ambiente das empresas, e é melhor que os estudantes brasileiros se armem para a cobrança" (O QUE ESTÁ, 1993, p. 89). A realidade se torna, em princípio, reativa àqueles que não se colocam cotidianamente em formação ainda que, mesmo aos que estão imersos na formatividade incessante, o mundo se evidencie igualmente hostil, apontando incessantemente ao preparo.

É a partir de tal construção da hostilidade que outras tantas racionalidades pautadas na insegurança formativa podem se constituir. Os discursos profissionais, por exemplo, sejam a partir da empresa, sejam de fora dela, se configuram comumente a partir de ordenamentos que estabelecem curricula vitae mínimos aos trabalhadores:

(...) a noção de cidadania torna a sociedade governável desde seu interior e provoca uma mutação de sentido na noção de liberdade do cidadão: ela se torna o resultado de um aprendizado de sociabilidade. Esboça-se um vasto projeto pedagógico que tem por objetivo formar cidadãos, o sujeito da sociedade civil, fazendo da sociabilidade individual o campo aberto e ilimitado de uma pedagogia que traz em seu núcleo a noção de dever (AVELINO, 2011, p. 101).

A moralidade formativa contemporânea, mediante discursos focados na formação do sujeito-cidadão, parece sempre surgir no entrelaçamento de liberdades individuais e necessidades sociais a cuidar, e isso desde o nascimento dos sujeitos a formar, como mostra o argumento da reportagem que trata dos excessos na proteção aos filhos: "do momento em que um bebê nasce até a hora em que ele entra na faculdade ou sai de casa, a questão central da sua existência é conquistar independência” (MACEDO; SANDOVAL, 2010, p. 110). Mas não pode haver aí qualquer excesso: para a reportagem, são comuns os casos de crianças que

\section{POLÊM!CA $\mid$ LABORE}


"quebram a bolha em que vivem" e "se transformam em adolescentes rebeldes além do aceitável, um atalho para que se tornem adultos frustrados" (p. 110).

A formação profissional, calcada em "atitudes diante da vida", ilustra bem esse desejo de tornar cidadão - sempre na medida necessária ao mercado. O homem a empregar é antes de tudo um indivíduo com valores associados a uma humanidade em desenvolvimento, e certo modo de ser cotidiano - sempre alcançável em termos de uma formação mais eficiente - se torna alvo da empresa. Também por isso, as formações dadas pelas mais diversas instituições encontrarão em suas maiores preocupações saberes que em muito ultrapassam a aquisição de competências técnicas para o trabalho, e que outrora escapariam ao ambiente empresarial: valores como "criatividade", "autonomia", "higiene" e "apresentação pessoal" podem comparecer às ementas de cursos com os mais variados motes, espraiando a figura do "homem preparado para o trabalho" para todos os momentos da existência, e vice-versa. "Se você quiser ter um filho com possibilidade de ser feliz e realizado (nunca há garantias), proporcione a ele a liberdade possível em cada etapa de sua vida" (MACEDO; SANDOVAL, 2010, p. 116); substitua, nesta última afirmativa, as palavras "filho" por "empregado" e "vida" por "trabalho", e o discurso caberá perfeitamente no mais novo manual de orientação aos gestores de uma empresa bem-sucedida.

O cidadão engajado não está sozinho: a boa existência individual sempre traz, consigo, a benevolência da ação no interior de uma "coletividade", comumente apresentada no interior de discursos de risco social, como no caso do preâmbulo de um importante documento da UNESCO (1998), a Declaração Mundial sobre Educação para Todos:

(...) o mundo tem que enfrentar um quadro sombrio de problemas, entre os quais: o aumento da dívida de muitos países, a ameaça de estagnação e decadência econômicas, o rápido aumento da população, as diferenças econômicas crescentes entre as nações e dentro delas, a guerra, a ocupação, as lutas civis, a violência: a morte de milhões de crianças que poderia ser evitada e a degradação generalizada do meio-ambiente. Esses problemas atropelam os esforços envidados no sentido de satisfazer as necessidades básicas de aprendizagem (UNESCO, 1998, p. 1).

A partir de imagens como essa, que de alguma forma imprimem à contemporaneidade certo número de desqualificações, são elaborados discursos de correção; deles deriva, no âmbito da formação e de suas já mencionadas relações com a laboralidade, a construção de enunciados focados em mudanças necessárias, que imprimem às transformações buscadas no interior da formatividade um sentido de urgência constante e de radicalidade. As intensas

\section{POLÊM!CA $\mid$ LABORE}


mutações são, ao mesmo tempo, preocupantes e louváveis, e é nessa dupla adjetivação que elas se potencializam como modos de fazer atentar para o viés formativo e laboral da existência: “A economia que se constrói sobre as ruínas tem muitos lugares, mas eles estão reservados a quem possuir energia e disciplina para seguir as constantes mudanças de rumo" (O QUE ESTÁ, 1993, p. 90); afinal de contas é "a diversidade, a complexidade e o caráter mutável das necessidades básicas de aprendizagem" (UNESCO, 1998, p. 3) que estarão na base da exigência por uma redefinição contínua do alcance da formação, diante de uma realidade tão mutável.

Os caminhos da formatividade, com suas crises e oportunidades globais, imprimem à existência um sentido de perseguição de objetivos e engajamento social. Muitos dos atuais dispositivos aptos a funcionar na sociedade atual parecem calcados em um desejo de incluir a todos. Ele está em diversos lugares: nos apelos, feitos por um documento técnico colaborativo (AÇÃO EDUCATIVA et. al., 2007), à seleção grupal e consensual de prioridades de avaliação de indicadores de qualidade da escola, por meio de trabalhos em grupos e, a partir daí, da formação de um grupo de grupos, para se "ouvir o que cada um tem a dizer e debater sobre o retrato que a comunidade escolar está tirando da escola" (p. 13); ou, no caso de outra proposição oficial, na garantia do "clima de parceria entre todos e uma consciência de rede" (UNICEF, 2011, p. 20), característica dos municípios que "garantem o direito de aprender" (p. 2), que entre outras características apresentam "espaços de planejamento e definição de metas coletivas" (p. 20), "respeito pelas decisões e corresponsabilidade pelos resultados" (p. 24) e "documentos norteadores" que, em comum, "têm a forma participativa como foram construídos" (p. 25).

Os discursos de totalidade têm alguns desdobramentos importantes. Constroem uma profusão de grupos diferenciados - "refugiados", “pobres”, “trabalhadores”, "populações de periferias urbanas e zonas rurais", "trabalhadores migrantes”, "povos indígenas", "minorias étnicas, raciais e linguísticas" (UNESCO, 1998, p. 4) - para os quais a produção formativa não deixará, a partir de então, de se voltar, produzindo legislações, discussões e institucionalidades específicas. Legitimam, por outro lado, enunciados que apontam para o empresariamento das relações sociais. Veja-se, por exemplo, o caso do sucesso atribuído a uma instituição social, em uma reportagem:

\section{POLÊM!CA $\mid$ LABORE}




\begin{abstract}
A Casa é uma fundação mantida com recursos do governo do Estado e por uma pequena mensalidade paga pelos seus habitantes (...). Para ajudar na sua manutenção, os estudantes têm alguns deveres bastante peculiares - cuidam da limpeza e da cozinha ou trabalham no campo, ajudando a tocar as duas granjas e uma fazenda que a Casa possui nas redondezas da cidade (REPÚBLICA, 1990, p. 15).
\end{abstract}

De tal atuação colaborativa deriva, então, uma conclusão fundamental: "para os moradores mais velhos, o segredo para a manutenção da Casa (...) está na capacidade de cada morador entender que ali não existem hóspedes, mas sócios de um mesmo empreendimento" (REPÚBLICA, 1990, p. 15). Tal como acontece com tantos elementos associados aos modos de existência dos sujeitos, transformados, por meio de planejamentos familiares ou projetos de vida em orientações específicas de uma realidade empresarial, é agora também a partir do trabalho em equipe que se constituirá a boa vida-trabalho do sujeito a formar.

Em terceiro lugar, os discursos de totalidade intensificam o sentido social da participação por eles almejada. Daí talvez o desejo de realizar trabalhos comunitários, anunciado por $70 \%$ dos jovens entrevistados por uma famosa pesquisa (BOX 1824, 2011). O cidadão socialmente engajado se tornou o fetiche de uma sociedade que encontrou no apelo à ação e à formação de todos mais uma de suas possibilidades de investimento nas subjetividades. Unido aos amplos investimentos institucionais focados no engajamento social, nasce um tipo de formação-cidadania que opera em um cotidiano minucioso, a partir das vivências e convivências do indivíduo comum.

\title{
Impressões finais
}

Complexidades, mensurabilidades, incompletudes e engajamentos. Os movimentos dispersivos do dispositivo de formação são muitos. Em grande parte, derivam do encontro entre as razões mercadológicas contemporâneas - "ontológicas" à própria ideia de Estado, na medida em que a liberdade de mercado funciona como "princípio organizador e regulador" do funcionamento estatal (FOUCAULT, 2008, p. 158) - e a construção cotidiana de uma demanda intensa pela formatividade individual. A formação, nesse sentido, parece atenta à "sociedade empresarial" que se constitui a partir da mentalidade concorrencial que ascende com o neoliberalismo, e que não tarda em encarnar nas individualidades, nelas imprimindo as resultantes de um conjunto de racionalidades que encontra no funcionamento empresarial e na produção suas maiores bases. Como "poder enformador da sociedade” (p. 203), a relação

\section{POLÊM!CA $\mid$ LABORE}


mercado-concorrência-empresa termina por alçar a empresa, de lugar institucional, a uma "maneira de se comportar no campo econômico"; e constitui um indivíduo que é, ele próprio, "uma espécie de empresa para si mesmo" (p. 310) - o homem-empresa sabe colocar sua vida, e a gestão a ela inerente, em termos de um gerenciamento profissional, com fórmulas, matrizes de planejamento e análise de resultados. Seu olhar para sua existência passa, portanto, a tomar como base certos critérios empresariais de controle e produtividade.

O que o dispositivo formativo em suas configurações atuais parece fazer é operar a partir do homem do consumo e da empresa que nele se estabelece. Declarando a falta de qualificação, definindo a partir dela as necessidades formativas e permitindo inferências analíticas e comparativas sobre os resultados quanto ao preparo do indivíduo para a vida, as operações discursivas oriundas da construção da formação na atualidade instauram, definitivamente, o continuum formação-trabalho-existência, tomado sempre a partir de um senso de preparo laboral e individualizado.

Veja-se que essa forma mercadológica de se contemplar a formatividade não carrega consigo qualquer naturalidade. Noguera-Ramirez (2011), em um importante estudo das teorizações que constituíram as tradições pedagógicas modernas, encontra um triplo caminho de desenvolvimento dos fundamentos do que entende como modernidade educativa: uma tradição germânica, que imprime à formação uma abrangência que ultrapassa a própria educação e instrução; uma tradição francófona que compreende o esforço educativo no âmbito de uma profusão de "ciências da educação" e uma anglo-saxônica diretamente voltada ao currículo como forma de organização das relações entre ensino e aprendizagem. O que parece visível, ao se contemplar os regimes discursivos cujos indícios foram aqui discutidos, é que o dispositivo formativo neles apresentado funciona em uma espécie de recorte que atravessa essas três matrizes: gerando currículos extensos, complexificações formativas e saberes especializados, a hiperformatividade contemporânea aponta para uma espécie de crescimento horizontal - associado às teorizações por ela agregadas - que se associa a uma ampliação vertical - materializada na quantidade de aquisições formativas que compõe o bem viver (e que tendem ao infinito) -, por meio de uma corrida de base mercadológica para a qual movimentos de resistência se tornam cada vez mais rarefeitos.

Com traços bem marcados nas últimas décadas, a relação entre carreira e formatividade, obviamente, não é novidade, e são bastante comuns as narrativas que associam

\section{POLÊM!CA $\mid$ LABORE}


os caminhos educacionais às melhoras nos modos de existir laborais - visíveis notadamente nas reflexões foucaultianas sobre a sociedade disciplinar, e que incluem interessantes exemplos de produção educacional da laboralidade, associados à produção do soldado, do médico ou do professor (FOUCAULT, 1987). É em tal movimento disciplinar que, já no século XIX, um estudioso como Frederic Taylor, em seus afãs de cientifização do trabalho, colocava como um dos objetivos de seu método o de "selecionar o melhor trabalhador para cada serviço, passando em seguida a ensiná-lo, treiná-lo e formá-lo, em lugar do antigo costume de deixar a ele que selecionasse o seu serviço e se formasse, da melhor maneira possível” (GERENCER, 1970, p. 21). Ocorre, no entanto, que tal aproximação deixa, pela dispersão dos discursos formativos na contemporaneidade, de ser circunstancial, de certa forma subordinada a um olhar mais amplo sobre a moralidade do sujeito, e passa a ser condição primeira da fala sobre a formação, inclusive moral, do próprio indivíduo. $\mathrm{O}$ curriculum vitae parece, então, atualizado em uma vida curricular, por meio de uma dispersão de racionalidades associadas à formação que toma a todos os lugares e espaços sociais; ultrapassa, dessa maneira, os ambientes formalmente voltados à educação e à profissionalização, alcançando espaços informais de desenvolvimento e, para além de tudo isso, relações as mais cotidianas - como aquelas que se estabelecem em encontros outrora despretensiosos (qualquer reunião de estudo carece, hoje, de uma certificação a ela associada), ou mesmo na leitura de uma revista semanal.

Figura - 1: Espraiamento das racionalidades formativas

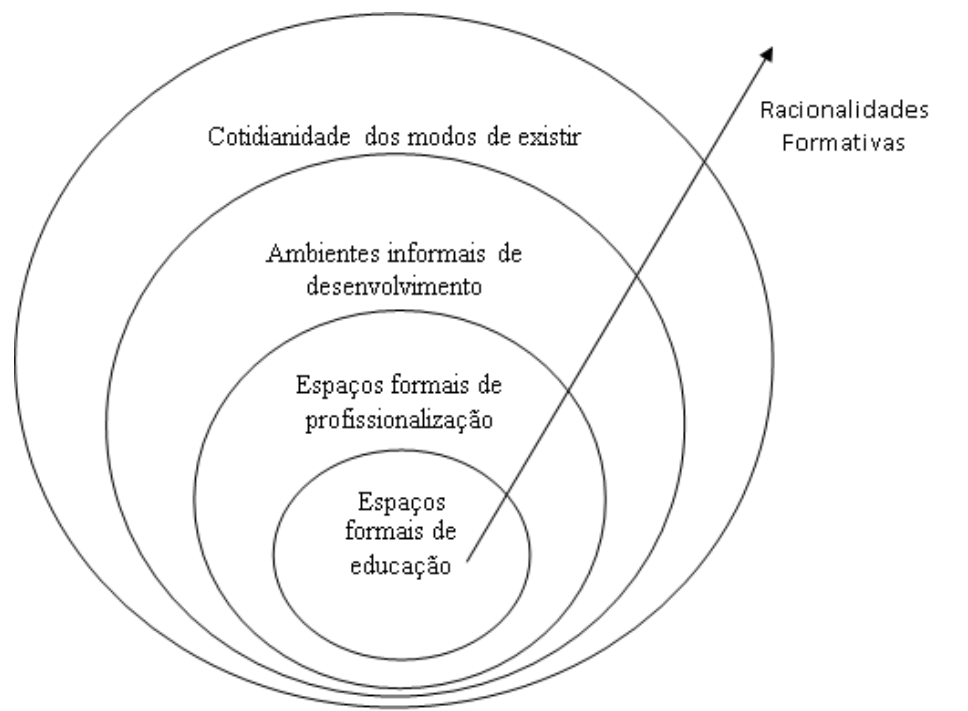

Fonte: Elaboração própria.

\section{POLÊM!CA $\mid$ LABORE}


Da educação dos filhos aos cuidados com o planeta, do divã ao escritório, operam movimentos de dispersão que terminam por estabelecer uma natureza própria e historicamente contingente à formatividade, capaz de converter o "bom homem" em um "bom trabalhador", tenha ele como foco os processos rigorosamente associados a sua realidade profissional ou as demais operações sobre sua existência. O cidadão a formar não precisa apenas estar preparado para o mercado, mas também para as formas de existir, transpassadas por racionalidades mercadológicas que atualmente lhes dão sentido, e tudo, inclusive a moralidade, pode então ser arrolado em termos de uma capitalização das formas de viver. Os sonhos de uma normatização máxima das condutas laborais, de alguma forma emergentes nas reflexões de Frederic Taylor (1970), talvez tenham chegado onde Comenius (2002), em seus anseios por uma Didactica Magna capaz de ensinar tudo a todos, jamais teria sido capaz.

\section{Referências}

A BRINCADEIRA da nova era. Revista Veja, nº 1265, p. 88-94, dez/1992.

A CONSTRUÇÃO do cérebro. Revista Veja, no 1436, p. 84-89, mar/1996.

A REVOLUÇÃO que liquidou o emprego. Revista Veja, nº 1362, p. 88-95, out/1994.

AÇÃO EDUCATIVA et. al. Indicadores da Qualidade na Educação. $3^{\text {a }}$ ed. ampliada. São Paulo: Ação Educativa, 2007.

ANER. Revistas em alta para o consumidor. 2009. Disponível em: <http://www.aner.org.br/Conteudo /noticias/revistas-em-alta-para-o-consumidor-145732-1.asp>. Acesso em: 27 mai. 2010.

ANTUNES, Camila. Como avaliar as escolas. Revista Veja, nº 1985, p. 124-125, dez/2006.

AVELINO, Nildo. Governamentalidade e democracia liberal: novas abordagens em Teoria Política. Revista Brasileira de Ciência Política, n. 5, Brasília, jan/jul. 2011, p. 81-107.

BAUMAN, Zigmunt. Modernidade líquida. Rio de Janeiro: Jorge Zahar, 2001.

O mal-estar da pós-modernidade. Rio de Janeiro: Jorge Zahar, 1998.

BRASIL. Decreto 6.755, de 29 de janeiro de 2009 - Institui a Política Nacional de Formação de Profissionais do Magistério da Educação Básica, disciplina a atuação da Coordenação de Aperfeiçoamento de Pessoal de Nível Superior -CAPES no fomento a programas de formação inicial e continuada, e dá outras providências. Diário Oficial da União, Brasília, no 21, p. 1-2. 2009(a).

Portaria $\mathrm{n}^{\circ} 833$, de 16 de setembro de 2009 - Estabelece as diretrizes nacionais para o funcionamento dos Fóruns Estaduais Permanentes de Apoio à Formação Docente, criados pelo Decreto 6.755, de 29 de janeiro de 2009. Diário Oficial da União, Brasília, nº 178, p. 26, 2009(b).

Instituto Nacional de Estudos e Pesquisas Anísio Teixeira. Portaria n 128. Diário Oficial da União, Brasília, n. 153, p. 9-10, 2008.

\section{POLÊM!CA $\mid$ LABORE}


Resolução CNE/CP n ${ }^{\circ}$ 1, de 15 de maio de 2006 - Institui Diretrizes Curriculares Nacionais para o Curso de Graduação em Pedagogia, licenciatura. Diário Oficial da União, Brasília, nº 92, p. 11, 2006(a).

Resolução FNDE n 20, de 17 de abril de 2006 - Estabelece as orientações e diretrizes para assistência financeira suplementar a projetos educacionais, no âmbito da Educação Básica, no exercício de 2006. Diário Oficial da União, Brasília, nº 74, p. 10, 2006(b).

Decreto $n^{\circ}$ 5.626, de 22 de dezembro de 2005. Regulamenta a Lei no 10.436, de 24 de abril de 2002, que dispõe sobre a Língua Brasileira de Sinais - Libras, e o art. 18 da Lei no 10.098, de 19 de dezembro de 2000. Diário Oficial da União, Brasília, nº 246, p. 28, 2005.

Resolução CNE/CEB no 2, de 11 de setembro de 2001 - Institui Diretrizes Nacionais para a Educação Especial na Educação Básica. Diário Oficial da União, Brasília, no 177, p. 39-40, 2001.

. Resolução CEB/CNE nº 2, de 19 de abril de 1999 - Institui Diretrizes Curriculares Nacionais para a Formação de Docentes da Educação Infantil e dos anos iniciais do Ensino Fundamental, em nível médio, na modalidade Normal. Diário Oficial da União, Brasília, no 76, p. 97, 1999(a).

Lei no 9.795, de 27 de abril de 1999 - Dispõe sobre a educação ambiental, institui a Política Nacional de Educação Ambiental e dá outras providências. Diário Oficial da União, Brasília, no 79, p. 41, 1999(b).

BOX 1824. O sonho brasileiro. 2011. Disponível em: <https://pt.slideshare.net/fernandapugliero/sonhobrasileiro-box-1824>. Acesso em: 22 mai. 2017.

COMENIUS, Iohannes Amos. Didática Magna. São Paulo: Martins Fontes, 2002.

DELEUZE, Gilles. Foucault. São Paulo: Brasiliense, 2005.

FERREIRA, Fernando Ilídio. Reformas educativas, formação e subjectividades dos professores. Revista Brasileira de Educação, v. 13, n. 38, maio/ago. 2008. p. 239-251.

FIMYAR, Olena. Governamentalidade como Ferramenta conceitual na pesquisa de políticas educacionais. Educação e Realidade, v. 34, n. 2. maio/ago. 2009. p. 35-56.

FOUCAULT, Michel. Nascimento da Biopolítica. São Paulo: Martins Fontes, 2008.

O que é a crítica? Tradução de Gabriela Lafetá Borges. Disponível na internet: www.unb.br/fe/tef/filoesco/foucault/critique.html. Acesso em: 13 abr. 2007. (2007)

O sujeito e o poder. In: RABINOW, P; DREYFUS, H. Michel Foucault - Uma trajetória filosófica: para além do estruturalismo e da hermenêutica. Rio de Janeiro: Forense Universitária, 1995. p. 231-249.

História da Sexualidade I: A vontade de saber. Rio de Janeiro: Graal, 1988.

Vigiar e Punir: história da violência nas prisões. Petrópolis: Vozes, 1987.

GERENCER, Pavel. Vida e obra de Taylor à guisa de prefácio. In: TAYLOR, F. W. Princípios de Administração Científica. 7 ed. São Paulo: Atlas, 1970. p. 11-23.

GRANADEIRO, Cláudia. Histórias para contar. Revista Veja, n 1724, p. 130-131, out/2001.

LAWN, Martin. Os professores e a fabricação de identidades. Currículo sem Fronteiras, v. 1, n. 2, p. 117-130, jul/dez. 2001.

\section{POLÊM!CA $\mid$ LABORE}

Polêmica - Revista Eletrônica da Uerj - Rua São Francisco Xavier, 524, $1^{\circ}$ andar

bloco D, sl.1001 • Tels.: +55 21 2334-4088/4087 • http://www.e-publicacoes.uerj.br/index.php/polemica/index

http://www.labore.uerj.br • laboreuerj@yahoo.com.br 
MACEDO, Daniela; SANDOVAL, Gabriella. Excesso de proteção faz mal ao seu filho. Revista Veja, n 2160 , p. 108-116, abr/2010.

NA CARTEIRA ao lado. Revista Veja, nº 1175, p. 42-48, mar/1991.

NETO, João Sorima. O funil estreitou. Revista Veja, nº 1473, p. 116-122, dez/1996.

NOGUERA-RAMIREZ, Carlos Ernesto. Pedagogia e governamentalidade ou Da Modernidade como uma sociedade educativa. Belo Horizonte: Autêntica, 2011.

O QUE ESTÁ mudando nas profissões. Revista Veja, nº 1305, p. 84-90, set/1993.

PAIS e filhos com hora marcada. Revista Veja, nº 1506, p. 82-89, jul/1997.

REPÚBLICA aberta. Revista Veja, no 1130. P. 15-17, mai/1990.

SOUZA, Okky de; VIEIRA, Vanessa. A vida com instruções. Revista Veja, no 2042, p. 54-61, jan/2008.

TAYLOR, Frederic Winslow. Princípios da Administração Científica. 7. ed. São Paulo: Atlas, 1970.

UNESCO. Padrões de Competência em TIC para professores: Diretrizes de implementação. UNESCO, 2009. Disponível em: 〈http://unesdoc.unesco.org/images/0015/001562/156209por.pdf〉. Acesso em: 12 ago. 2011.

Declaração Mundial sobre Educação para Todos: satisfação das necessidades básicas de aprendizagem - Jomtien, 1990. Unesco, 1998. Disponível em:

<http://unesdoc.unesco.org/images/0008/000862/086291por.pdf>. Acesso em: 17 out. 2010.

UNICEF. Redes de Aprendizagem - Boas práticas de municípios que garantem o direito de aprender.

Disponível em: <http://www.unicef.org/brazil/pt/Redes_de_aprendizagem.pdf>. Acesso em: 08 nov. 2011.

Recebido em: 24/08/2016.

Aceito em: 11/05/2017.

\section{POLÊM!CA $\mid$ LABORE}

Polêmica - Revista Eletrônica da Uerj - Rua São Francisco Xavier, 524, $1^{\circ}$ andar bloco D, sl.1001 • Tels.: +55 21 2334-4088/4087 • http://www.e-publicacoes.uerj.br/index.php/polemica/index http://www.labore.uerj.br • laboreuerj@yahoo.com.br 